\title{
OXIDATIVE DAMAGE TO PROTEINS AND LIPIDS DURING AGEING
}

\author{
Kuka S., Tatarkova Z., Kaplan P.
}

Department of Medical Biochemistry, Jessenius Faculty of Medicine, Comenius University, Martin, Slovak Republic

\begin{abstract}
The present work is a theoretical study in the field of monitoring oxidative damage to proteins and lipids during ageing. The basic terminology and interactions are discussed as well as the sources of oxidants and their elimination through antioxidant protection. We focus on the effects of oxidative stress on the biomolecules (proteins, lipids and DNA), the role of mitochondria, antioxidants, physical activity and caloric restriction in relation to ageing. Previous research indicates the crucial role of mitochondria in the ageing process by their formation of oxidants, the accumulation of oxidative damage to mtDNA and other biomolecules leading to impairment of mitochondrial function, energy failure, apoptosis and necrosis. Although the role of oxidative stress in the ageing process is evident and well documented, the precise mechanisms of its relationships remain largely unknown. Further research is needed to clarify them and to show ways to slow down the ageing process.
\end{abstract}

Key words: ageing, oxidative damage, biomolecules, mitochondria

\section{INTRODUCTION}

Oxidative damage to biomolecules during ageing is a topic of interest of many scientists, especially for severity ageing accompanying effects. Ageing is inevitable and is characterized by a progressive deterioration in physiological functions and metabolic processes, ultimately leading to morbidity and mortality (1). There exist many theories of ageing. The free radical theory of ageing (2) proposes that free radicals, a by-product of normal metabolism, cause oxidative damage to macromolecules. Their accumulation causes cellular dysfunction with age and eventually cell death. Over time this theory has been further refined to reflect the fact that mitochondria are at the same time major sources and a target of free radicals and other reactive oxygen species (ROS). The main features of mitochondrial theory of ageing are: increased ROS production, mitochondrial DNA (mtDNA) damage accumulation and progressive respiratory chain dysfunction (3). Mitochondria ensure energetical needs of most tissues and they play a major role in cell survival. Therefore their dysfunction is causatively linked to the ageing process and a number of human degenerative diseases such as Parkinson's or Alzheimer's disease (4).

Recently, the lifespan of different organisms can be manipulated by altering ROS metabolism, especially at the level of scavenging systems, through exogenous and/or endogenous interventions. Among these, supplementation with dietary antioxidants has been one of the approaches utilized to test the free radical theory of ageing, and finally, to try to reduce the impact of age-related dysfunctions (5). Physical activity and caloric restriction represent other factors investigated in their relation to ageing.

\section{OXIDANTS, OXIDATIVE DAMAGE TO PROTEINS AND LIPIDS, ANTIOXIDANTS}

Oxidative damage to biomolecules is caused by free radicals and other (nonradical) reactive forms of oxygen and nitrogen, especially superoxide radical $\mathrm{O}_{2}{ }^{--}$, hydrogen per-

Address for correspondence:

Ing. Stanislav Kuka, Department of Medical Biochemistry, Jessenius Faculty of Medicine, Comenius University, Malá Hora 4, 03754 Martin, Slovak Republic

Phone: 043/26 33 407; e-mail: kuka@jfmed.uniba.sk 
oxide $\mathrm{H}_{2} \mathrm{O}_{2}$, singlet oxygen $\Delta^{1} \mathrm{O}_{2}$, hydroxyl radical $\mathrm{OH}$ and nitric oxide NO. Oxidant sources can be divided into external and internal. Although internal sources (mitochondria and others) are considered as crucial, some external sources, e.g. smoking, air pollution or UV radiation, can also significantly contribute to oxidative stress.

Oxidative damage to proteins under conditions of oxidative stress involves several chemical reactions such as: amino acid side chains oxidation, fragmentation of polypeptide chains, generation of cross linkages and conformation changes. These oxidative modifications are usually irreversible and lead to serious disruption of protein function (6). The exception is the reversible oxidation of side chains of methionine and cysteine. This allows the recovery of protein property and also elimination of ROS, which is important in protecting cells from oxidative stress (7).

The oxidation of lipids is especially damaging because the formation of lipid peroxidation products leads to a spread of free radical reactions (8). Lipid peroxidation (LPO) concerns in particular polyunsaturated fatty acids (PUFA) that gradually form conjugated dienes and hydroperoxides after the radical attack. Lipid peroxidation leads also to the formation of aldehyde by-products, including malondialdehyde (MDA), 4hydroxy-2-nonenal (HNE) and acrolein, which are often refered to as advanced lipooxidation end products (ALEs).

Antioxidant is a term widely used but rarely defined. Halliwell and Gutteridge (9) have proposed a broad definition of an antioxidant as ,any substance that, when present at low concentrations compared with those of an oxidizable substrate, significantly delays or prevents oxidation of that substrate". Because antioxidants do not work in the body separately, more important than monitoring the activities of individual antioxidants is the determination of the total antioxidant capacity (10). Oxidative and antioxidative processes are associated with the electron transfer effect on the redox state of cells and the organisms. The changed redox state stimulates or inhibits activities of various signal proteins, resulting in a changed ability of signal pathways and the fate of the cells. Recently, the idea that oxidative stress is not always harmful has been accepted (11).

\section{AGEING AND MITOCHONDRIA}

Previous research indicates the crucial role of mitochondria in the ageing process by: their formation of oxidants; the accumulation of oxidative damage to mitochondrial DNA; and other biomolecules leading to an impairment of mitochondrial function, energy failure, apoptosis and necrosis. Interest in mitochondria relating to ageing has been apparent for a long time as shown in the article written by D. Harman in 1972 (12). Since that time, many studies have been devoted to that subject and, although the role of mitochondria and oxidative stress in the ageing process is evident and well documented, the precise mechanisms of their relationships remain largely unknown.

The mitochondria are, at the same time, major sources and a target of free radicals and other ROS $(13,14)$. ROS are generated in mitochondria as a by-product of energy metabolism; part of the oxygen $(2-4 \%)$ leaks in the form of superoxide from electron transfer chain (respiratory chain) complexes (15). Although superoxide is not characterized by high reactivity to biomolecules, more dangerous products are formed from it: hydrogen peroxide, singlet oxygen and hydroxyl radical (6). Superoxide production occurs in the respiratory chain, localized to complexes I and III (16). In complex I, oxygen is likely to be reduced to superoxide at two sites: one associated with NADH oxidation in the mitochondria matrix; the second one relates to the reduction of ubiquinone in the membrane (17). Complex III leads to the formation of ROS in the binding site of antimycine A (18). Enzyme complexes oxoglutarate dehydrogenase and pyruvate dehydrogenase, in the mitochondrial matrix, are also sites of ROS production (19). Wang et al. (20) discovered a quantal mode of mitochondrial ROS production. They 
showed that individual mitochondria undergo spontaneous bursts of superoxide generation, termed "superoxide flashes", indicated with the aid of a novel mitochondrial matrix-targeted superoxide indicator (circularly permuted yellow fluorescent protein cpYFP). Individual flashes are triggered by transient openings of the mitochondrial permeability transition pore (mPTP) and are fuelled by electron transfer complexesdependent superoxide production. During cardiac hypoxia/anoxia it is decreased, whereas, during reperfusion, a flurry of superoxide flash activity occurs.

Mitochondria and other cellular compartments are a target for oxidative modifications during ageing. The results of the study from this laboratory (21) suggest a different mechanism of oxidative modification in rat heart compartments e.g. the level of lysine conjugates increased with age in homogenate while the level of modified tryptophan increased in mitochondria.

In addition to free radicals, ALEs play a significant role in oxidative damage to biomolecules during ageing: HNE creates protein adducts and induces formation of ROS in mitochondria, probably due to lipid- and protein-modification of the inner mitochondrial membrane (22). MDA shows similar adverse effects, which inhibit especially pyruvate dehydrogenase, oxoglutarate dehydrogenase, complexes I and II activities in rat liver mitochondria (23).

Many studies are focused on changes of mitochondrial respiratory chain complexes activities during ageing. The results on rats and mice mitochondria are relatively controversial: a decline in activities of the complexes I - IV with age $(24,25)$; decreased activities of only some complexes (others without changes), e.g. decrease of only V (26) or of I and V (27) even the contradictory activity changes: decline of complexes I and V, increase of II and III (28). The changes in the activities with age can be due to various factors: the accumulation of oxidative damaged mitochondrial proteins, as provided by the decrease of thiol groups and the increase of protein-HNE adducts and dityrosines (25). Similarly, another study (28) reports correlations between decreases in complexes $\mathrm{I}$ and $\mathrm{V}$ activities and the increase in oxidative modification of their subunits. However, activity changes may be related to oxidative damage to other components of the inner mitochondrial membrane, such as cardiolipin, supplementation of which restores agedecreased complex I activity (29). A similar effect; activity restoration of several complexes, was achieved by application of L-carnitine (24). Some studies (1, 27) suggest links between changes in respiratory chain function and oxidative damage to DNA (especially mtDNA), leading to changes in expression of genes coding respiratory chain complexes. Mitochondrial DNA is more prone to oxidative damage in comparison to nuclear DNA. Consequently, the decline in activity of complex I, composed of the largest number of subunits coded by mtDNA, has often been seen (1). Gomez et al. (30) report another mechanism of respiratory chain function deterioration with age. According to these authors, the phenomenon may arise in part from dissociation of large hypermolecular assemblies termed "supercomplexes". Mitochondrial proteins from young and old rat hearts were separated (blue native PAGE), protein bands analysed (LCMALDI-MS/MS) and protein levels quantified by densitometry. Results showed that supercomplexes composed of various stoichiometries of complex I, III and IV were observed, and declined significantly with age, without changes in concentrations of single complexes I - IV. The deterioration in respiratory chain supercomplexes may be an important underlying factor for loss of cardiac bioenergetics with age.

\section{AGEING AND ACCUMULATION OF OXIDATIVE DAMAGE}

The possibility that ROS/RNS-mediated protein damage contributes to the ageing process is supported by results of many studies showing that ageing is associated with the accumulation of such protein damage. The accumulation of protein damage is 
a complex function of a multiplicity of factors that govern the intracellular levels of ROS/RNS, on the one hand, and a multiplicity of factors that govern the degradation and/or repair of damaged proteins, on the other (31). Repair/degradation mechanism is part of the body's protective system against the negative effects of ROS/RNS. The functionality of the system is not perfect, to which also contribute ROS/RNS and secondary products of their reactions. The result is the accumulation of oxidative modified biomolecules that participate in the pathogenesis of various diseases. These include: cardiovascular diseases $(6,32)$; neurodegenerative diseases; cancer, many lung diseases (33, 34); different genetic diseases such as Down's syndrome (35); some eye diseases (36); digestive diseases, especially of the liver (37); rheumatoid arthritis and other chronic inflammatory diseases; diabetes; and related complications. A growing number of illnesses (schizophrenia, epilepsy, multiple sclerosis, psoriasis) with increased oxidative damage suggests its essential role in the pathogenesis of the diseases (38).

The protein maintenance system ensures repair of sulfur-containing amino acid oxidation products, either by the thioredoxin/thioredoxin reductase system or by the peptide methionine sulfoxide reductase system. Other, irreversible amino acid oxidative modifications are eliminated by the destruction of protein. Degradation of oxidized proteins in the cytosol is mainly achieved by the ubiquitin-proteasome system. Ubiquitin, small protein of 76 amino acid residues, is used for labeling of oxidized proteins that should be degradated (39). Lon protease provides degradation of the oxidized proteins in mitochondria. The lysosomal pathway has also been implicated during oxidative stress throughout a chaperone mediated autophagy. Repair/degradation systems become less efficient during ageing, leading to an increased intracellular load of damaged proteins and to the formation of protein aggregates (40). The aggregates of lipofuscin (highly oxidized, cross-linked, insoluble, not degradable, yellow-brown product) have been found in various cell types including heart, liver, kidney, neuronal tissue and dermal tissue. They are associated with the life span of a single postmitotic cell and, consequently, of the whole organism (41).

An accompanying feature of ageing cells is also the formation of the advanced glycation end products (AGEs). AGEs are a heterogeneous group of bioactive molecules that are formed by the nonenzymatic glycation of proteins, lipids and nucleic acids. Humans are exposed to AGEs produced in the body, especially in individuals with abnormal glucose metabolism, and AGEs ingested in foods. AGEs cause widespread damage to tissues through upregulation of inflammation and cross-linking of collagen and other proteins (42).

\section{AGEING, ANTIOXIDANTS, PHYSICAL ACTIVITY AND CALORIC RESTRICTION}

Ageing of humans and other organisms is accompanied by many negative phenomena (see above). There is, not surprisingly, an age-old attempt to find a way and means to eliminate these phenomena, or at least delay or mitigate. Ageing is an extremely complex process, with no factor operating in isolation. Therefore, the interpretation of results obtained in vitro experiments is usually of very limited validity and results obtained in vivo may often be different.

Ageing may cause a violation of oxidant and antioxidant balance in favor of oxidants by increasing their production and/or reducing antioxidant protection. Many experimental studies have examined the possibility of restoring the original balance by strengthening the antioxidant protection by antioxidant supplementation. Many antioxidants were tested e.g. lipoic acid alone or in combination with carnitine. Improved mitochondrial bioenergetics (43), reduced damage to mtDNA (44), decreased apoptosis (45) and increased activities of citrate cycle enzymes and respiratory chain complexes (46) in ageing rats' myocardium have been shown. Similar effects were also seen in the application of other antioxidants. Nevertheless, a clear conclusion on the role of antioxidants in ageing does not exist yet $(6,38)$. Based on the current data, if 
oxidative stress/damage (and therefore also antioxidants) plays a role in ageing, it is much more limited than previously thought. However, oxidative stress/damage may play a role in health span, i.e., the period of life during which the animal is free of agerelated pathologies, or may play a stronger role under conditions in which an animal is exposed to chronic stress over its life span, and may accelerate several features of the ageing process (47). As we have mentioned earlier, free radicals have also positive roles in the living organisms. Moreover, antioxidants may, in the non-physiological conditions, show the opposite - prooxidant effects. Example for this is the effect of ascorbic acid in the presence of excess $\mathrm{Fe}^{2+}$ ions. Thus, the imprudent administration of antioxidants may have a negative impact on the organism (11).

Adequate physical activity is another factor associated with ageing. Several studies indicate reduced production of $\mathrm{H}_{2} \mathrm{O}_{2}$ in myocardial mitochondria of physically active rats (48) or an increase of the life expectancy of the physically active mice from 9 to $19 \%$ (49). The mechanisms of this positive effect remain unclear. One possible mechanism is related to the change in the ratio of ROS formation and elimination. In spite of increased consumption of oxygen during physical activity, ROS production does not grow significantly because in respiratory state 3 (activity), the relative ROS production is much lower than in respiratory state 4 (resting respiration). However, physical activity and subsequent mild oxidative stress activate antioxidant protection by stimulating the expression of antioxidant enzymes (50). On the other hand, extreme physical activity leads to increased oxidative stress, probably due to muscle damage and subsequent inflammatory response (6).

Caloric restriction (CR) seems to be by far the most effective environmental manipulation that can extend maximum lifespan in many different species (51). Although the exact mechanism of action of CR is still unknown, the final effect is probably co-created by several mechanisms; not only by the reduction of energy metabolism. Li et al. (52) report that two main mechanisms leading to extended longevity during CR seem to be DNA methylation and histone modifications. Both of them are believed to dynamically influence the chromatin structure, resulting in expression changes of relevant genes. DNA methylation regulation involves DNA methyltransferase activation, resulting in silencing the expression of target genes such as $p 16^{I N K 4 a}$ and Ras due to its hypermethylation. Histone modifications include especially deacetylation effects due to activation of histone deacetylases Sirt1 and HDAC1, leading to down-regulation of genes such as p53, Foxo, Ku7O and p16 INK4a. Other authors (53) deny the independent action of these mechanisms and suggest that $\mathrm{CR}$ or CR-mimetic compounds (resveratrol) increase expression and/or activity of Sirt1, leading to increased histone deacetylation and, thereby, to increased DNA methylation. In spite of the fact that the precise mechanism is not completely known, these results suggest that epigenetic pathways play an important role in the beneficial effects of caloric restriction on lifespan.

\section{CONCLUSIONS}

Literary sources used in this review briefly document the current state of research on the problem of oxidative damage to critical biomolecules (proteins, lipids) and the role of damage in ageing. Oxidative changes are the result of an imbalance between production of free radicals and their elimination. The most important source of ROS and RNS include mitochondria that are the first targets of their harmful effects, leading to a progressive decline in mitochondrial function. Although the involvement of oxidative stress and damage to biomolecules in the ageing process is documented in many studies, the detailed mechanisms of this involvement still remain unclear. Unfortunately, many studies have published contradictory experimental results. To clarify and possibly manipulate the mechanisms acting together in the ageing process, further experiments are needed, carefully prepared, implemented and evaluated. 


\section{REFERENCES}

1. Judge S, Leeuwenburgh C. Cardiac mitochondrial bioenergetics, oxidative stress, and aging. Am J Physiol Cell Physiol. 2007; 292(6): C1983-92

2. Harman D. Aging: a theory based on free radicals and radiation chemistry. J Gerontol. 1956; 2: 298-300

3. Dufour E, Larsson NG. Understanding aging: revealing order out of chaos. Biochim Biophys Acta. 2004; 1658(1-2): 122-32

4. Osiewacz HD. Role of mitochondria in ageing and age-related disease. Exp Gerontol. 2010; 45(7-8): 465

5. Cocco T, Sgobbo P, Clemente M, Lopriore B, Grattagliano I, Di Paola M, Villani G. Tissue-specific changes of mitochondrials functions in aged rats: effect of a long- term dietary treatment with $\mathrm{N}$-acetylcysteine. Free Radic Biol Med. 2005; 38(6): 796-805

6. Kaplán P. Kardiovaskulárne ochorenia a volné radikály. P+M Turany, 2010; 120 s.

7. Stadtman ER. Protein oxidation and aging. Free Radical Research. 2006; 40(12): 1250-8

8. Catalá A. Lipid peroxidation of membrane phospholipids generates hydroxy-alkenas and oxidized phospholipids active in physiological and/or pathological conditions. Chem Phys Lipids. 2009; 157(1): 1-11

9. Halliwell B, Gutteridge JMC. Free radicals in biology and medicine : Antioxidant defences. 3rd ed. New York: Oxford Univ Press; 1999. Halliwell B, Gutteridge JMC eds.

10. Sivoňová M, Tatarková Z, Duračková Z, Dobrota D, Lehotský J, Matáková T, Kaplán P. Relationship between antioxidant potential and oxidative damage to lipids, proteins and DNA in aged rats. Physiol. Res. 2007; 56(6): 757-64

11. Duračková Z. Some current insights into oxidative stress. Physiol Res. 2010; 59(4): 459-69

12. Harman D. The biologic clock: the mitochondria? J Am Geriatr Soc. 1972; 20(4): 145-7

13. Zorov DB, Juhaszova M, Sollott SJ. Mitochondrial ROS-induced ROS release: an update and review. Biochim Biophys Acta. 2006; 1757(5-6): 509-17

14. Romano AD, Serviddio G, de Matthaeis A, Bellanti F, Vendemiale G. Oxidative stress and aging. Nephrol. 2010; 23(Suppl. 15): S29-36

15. Gao L, Laude K, Cai H. Mitochondrial patophysiology, reactive oxygen species, and cardiovascular diseases. Vet Clin North Am Small Anim Pract. 2008; 38(1): 137-55

16. Trifunovic A, Larsson NG. Mitochondrial disfunction as a cause of ageing. J Intern Med. 2008; 263(2): 167-78

17. Esterhazy D, King MS, Yakovlev G, Hirst J. Production of reactive oxygen species by complex I (NADH:ubiquinone oxidoreductase) from Escherichia coli and comparison to the enzyme from mitochondria. Biochemistry. 2008; 47(12): 3964-71

18. Zhang HM, Zhang Y, Zhang BX. The role of mitochondrial complex III in melatonin-induced ROS production in cultured mesangial cells. J Pineal Res. 2011; 50(1): 78-82.

19. Starkov AA, Fiskum G, Chinopoulos C, Lorenzo BJ, Browne SE, Patel MS, Beal MF. Mitochondrial alphaketoglutarate dehydrogenase complex generates reactive oxygen species. J Neurosci. 2004; 24(36): 7779-88

20. Wang W, Fang H, Groom L, Cheng A, Zhang W, Liu J, Wang X, Li K, Han P, Zheng M, Yin J, Mattson MP, Kao JP, Lakatta EG, Sheu SS, Ouyang K, Chen J, Dirksen RT, Cheng H. Superoxide flashes in single mitochondria. Cell. 2008; 134(2): 279-90

21. Babušíková E, Jesenák M, Račay P, Dobrota D, Kaplán P. Oxidative alternations in rat heart homogenate and mitochondria during ageing. Gen Physiol Biophys. 2008; 27(2): 115-20

22. Kaplán P, Tatarková Z, Račay P, Lehotský J, Pavlíková M, Dobrota D. Oxidative modifications of cardiac mitochondria and inhibition of cytochrome c oxidase activity by 4-hydroxynonenal. Redox Rep. 2007; 12(5): $211-8$

23. Long J, Wang X, Gao H, Liu Z, Liu C, Miao M, Liu J. Malonaldehyde acts as a mitochondrial toxin: Inhibitory effects on respiratory function and enzyme activities in isolated rat liver mitochondria. Life Sci. 2006; 79(15): 1466-7

24. Kumaran S, Subathra M, Balu M, Panneerselvam C. Age-associated decreased activities of mitochondrial electron transport chain complexes in heart and skeletal muscle: role of L-carnitine. Chem Biol Interact. $2004 ; 148(1-2): 11-8$

25. Tatarková Z, Kuka S, Račay P, Lehotský J, Dobrota D, Mištuna D, Kaplán P. Effects of aging on activities of mitochondrial electron transport chain complexes and oxidative damage in rat heart. Physiol Res. 2011; 60(2): 281-9

26. Davies SM, Poljak A, Duncan MW, Smythe GA, Murphy MP. Measurements of protein carbonyls, orthoand meta-tyrosine and oxidative phosphorylation complex activity in mitochondria from young and old rats. Free Radic Biol Med. 2001; 31(2): 181-90

27. Preston CC, Oberlin AS, Holmuhamedov EL, Gupta A, Sagar S, Syed RH, Siddiqui SA, Raghavakaimal S, Terzic A, Jahangir A. Aging-induced alterations in gene transcripts and functional activity of mitochondrial oxidative phosphorylation complexes in the heart. Mech Ageing Dev. 2008; 129(6): 304-12

28. Choksi KB, Papaconstantinou J. Age-related alterations in oxidatively damaged proteins of mouse heart mitochondrial electron transport chain complexes. Free Radic Biol Med. 2008; 44(10): 1795-805

29. Petrosillo G, Matera M, Moro N, Ruggerio FM, Paradies G. Mitochondrial complex I dysfunction in rat heart with aging: critical role of reactive oxygen species and cardiolipin. Free Radic Biol Med. 2009; 46(1): 88-94 
30. Gómez LA, Monette JS, Chavez JD, Maier CS, Hagen TM. Supercomplexes of the mitochondrial electron transport chain decline in the aging rat heart. Arch Biochem Biophys. 2009; 490: 30-35

31. Stadtman ER. Role of oxidant species in aging. Curr Med Chem. 2004; 11(9): 1105-12

32. Lee S, Park Y, Zuidema MY, Hannink M, Zhang C. Effects of interventions on oxidative stress and inflammation of cardiovascular diseases. World J Cardiol. 2011; 3(1): 18-24

33. Singh M, Nam DT, Arsenault M, Ramassamy C. Role of by-products of lipid oxidation in Alzheimer's disease brain: a focus on acrolein. J Alzheimers Dis. 2010; 21(3): 741-56

34. Fernández-Checa JC, Fernández A, Morales A, Marí M, García-Ruiz C, Colell A. Oxidative stress and altered mitochondrial function in neurodegenerative diseases: lessons from mouse models. CNS Neurol Disord Drug Targets. 2010; 9(4): 439-54

35. Palardó FV, Lloret A, Lebel M, d Ischia M, Cogger VC, Le Couteur DG, Gadaleta MN, Castello G, Pagano G. Mitochondrial dysfunction in some oxidative stress-related genetic diseases: Ataxia-Telangiectasia, Down Syndrome, Fanconi Anaemia and Werner Syndrome. Biogerontology. 2010; 11(4): 401-19

36. Shoham A, Hadziahmetovic M, Dunaief JL, Mydlarski MB, Schipper HM. Oxidative stress in diseases of human cornea. Free Radic Biol Med. 2008; 45(8): 1047-55

37. Moustafa AH, Ali M, Mohamed TM, Abdou HI. Oxidative stress and thyroid hormones in patients with liver diseases. Eur J Intern Med. 2009; 20(7): 703-8

38. Giustarini D, Dalle-Donne I, Tsikas D, Rossi R. Oxidative stress and human diseases: Origin, link, measurement, mechanisms, and biomarkers. Crit Rev Clin Lab Sci. 2009; 46(5-6): 241-81

39. Ciechanover A. The ubiquitin proteolytic system: from an idea to the patient bed. Proc Am Thorac Soc. 2006; 3(1): 21-31

40. Farout L, Friguet B. Proteasome Function in Aging and Oxidative Stress: Implications in Protein Maintenance Failure. Antioxid Redox Signal. 2006; 8(1-2): 205-16

41. Jung T, Bader N, Grune T. Lipofuscin: formation, distribution, and metabolic consequences. Ann N Y Acad Sci. 2007; 1119: 97-111

42. Semba RD, Nicklett EJ, Ferrucci L. Does accumulation of advanced glycation end products contribute to the aging phenotype? J Gerontol A Biol Sci Med Sci. 2010; 65(9): 963-75

43. Savitha S, Panneerselvam C. Mitochondrial membrane damage during aging process in rat heart: potential efficacy of L-carnitine and DL alpha lipoic acid. Mech. Ageing Dev. 2006; 27(4): 349-55

44. Savitha S, Panneerselvam C. Mitigation of age-dependent oxidative damage to DNA in rat heart by carnitine and lipoic acid. Mech Ageing Dev. 2007; 128(2): 206-12

45. Tamilselvan J, Jayaraman G, Sivarajan K, Panneerselvam C. Age-dependent upregulation of p53 and cytochrome c release and susceptibility to apoptosis in skeletal muscle fiber of aged rats: role of carnitine and lipoic acid. Free Radic Biol Med. 2007; 43(12): 1656-69

46. Sudheesh NP, Ajith TA, Janardhanan KK, Krishnan CV. Palladium alpha-lipoic acid complex formulation enhances activities of Krebs cycle dehydrogenases and respiratory complexes I-IV in the heart of aged rats. Food Chem Toxicol. 2009; 47(8): 2124-8

47. Salmon AB, Richardson A, Pérez VI. Update on the oxidative stress theory of aging: Does oxidative stress play a role in aging or healthy aging? Free Radic Biol Med. 2010; 48(5): 642-55

48. Judge S, Jang YM, Smith A, Selman C, Phillips T, Speakman JR, Hagen T, Leeuwenburgh C. Exercise by lifelong voluntary wheel running reduces subsarcolemmal and interfibrillar mitochondrial hydrogen peroxide production in the rat heart. Am J Physiol Regul Integr Comp Physiol. 2005; 289(6): R1564-72

49. Navarro A, Gomez C, López-Cepero JM, Boveris A. Beneficial effects of moderate exercise on mice aging: survival, behavior, oxidative stress, and mitochondrial electron transfer. Am J Physiol Regul Integr Comp Physiol. 2004; 286(3): R505-11

50. Ascensão A, Ferreira R, Magalhães J. Exercise-induced cardioprotection - biochemical, morphological and functional evidence in whole tissue and isolated mitochondria. Int $J$ Cardiol. 2007; 117(1): 16-30

51. Sinclair DA. Toward a theory of caloric restriction and longevity regulation. Mech Ageing Dev. 2005; 126: 987-1002

52. Li Y, Daniel M, Tollefsbol T. Epigenetic regulation of caloric restriction in aging. BMC Med. 2011; 9(1): 98 [Epub ahead of print]

53. Wakeling LA, Ions LJ, Ford D. Could Sirt1-mediated epigenetic effects contribute to the longevity response to dietary restriction and be mimicked by other dietary interventions? Age (Dordr). 2009; 31(4):327-41

Acknowledgement: This work was supported by grant VEGA 1/0028/11 from the Ministry of Education and Science of the Slovak Republic

Received: October, 15, 2011

Accepted: November, 29, 2011 